Friends, enemies or strangers? On relationships between public and private sector service providers in hybrid forms of governance

WORKING PAPER - PAPER ACCEPTED FOR PUBLICATION IN LAW AND POLICY, 2011

Jeroen van der Heijden

Australian National University, the Regulatory Institutions Network (RegNet)

University of Amsterdam, Amsterdam Law School

\begin{abstract}
Hybrid forms of governance have special attention in literature on regulatory reforms. It is often assumed that a combination of public and private sector involvement in a regulatory regime is superior to "pure public" or "pure private" regimes. By paying close attention to such hybrids, this paper finds that hybrids have two key dimensions. First, the "amount" of public and private sector involvement in a hybrid; and second, the relationship between these sectors. Contrary to the former dimension, the latter hardly gets any attention in scholarship. This article addresses that knowledge gap. It introduces a typology of hybrids based on these two dimensions. A brief case study is introduced to discuss the value of the focus on relationships between public and private sector service providers.
\end{abstract}




\title{
Friends, enemies or strangers? On relationships between public and private sector service providers in hybrid forms of governance ${ }^{1}$
}

\begin{abstract}
Hybrid forms of governance have special attention in literature on regulatory reforms. It is often assumed that a combination of public and private sector involvement in a regulatory regime is superior to "pure public" or "pure private" regimes. By paying close attention to such hybrids, this paper finds that hybrids have two key dimensions. First, the "amount" of public and private sector involvement in a hybrid; and second, the relationship between these sectors. Contrary to the former dimension, the latter hardly gets any attention in scholarship. This article addresses that knowledge gap. It introduces a typology of hybrids based on these two dimensions. A brief case study is introduced to discuss the value of the focus on relationships between public and private sector service providers.
\end{abstract}

\section{Introduction}

In recent years scholarship has become increasingly sensitive to the way in which public services are delivered to their users. Monopolist public service delivery by public sector agencies repeatedly proves inadequate, with many scholars pointing out effectiveness and efficiency issues. To overcome such inadequacies private sector agencies are often introduced in the delivery of public services such as healthcare, transportation, energy and telecommunication. However, this privatization is also often found to result in shortfalls and repeatedly issues concerning equity and accountability are reported. Privatization appears to be a cure that comes with its own diseases.

Aiming at combining the strengths of both sectors and overcoming their weaknesses, today many forms of public service delivery may be typified as hybrid forms of governance, or "hybrids" for short (Evers, 2005; Noorderhaven, 1995). In hybrids both public and private sector agencies operate in the same field. Although the "amount" of public and private sector service providers in a hybrid is a core focus in studies on hybridization, this proportion is not the only

\footnotetext{
${ }^{1}$ This paper was partly written at the University of Oxford, Department of Politics and International Relations where the author held a position as Visiting Research Fellow in 20102011. The author wishes to thank the Department and especially Christopher Hood for all support. The author wishes to thank the three anonymous reviewers and editor of the journal for helpful comments. Special thanks to Peter May and Gwen for reading and reflecting on the many earlier drafts of this paper.

Address correspondence to Dr. Jeroen van der Heijden, Regulatory Institutions Network (RegNet), School of Regulation, J ustice and Diplomacy (RJD), College of Asia and the Pacific (CAP), HC Coombs Extension \#8, The Australian National University, Canberra ACT 0200, Australia. Telephone: +61 2612 51500; e-mail: jeroen@jeroenvanderheijden.net
} 
key feature of a hybrid. Another key feature is the interplay, or relationship between public and private sector parties in a hybrid. In this paper this relationship is looked upon as a part of the institutional setting within which the sectors operate. To date, this feature has had limited scholarly attention.

This article argues that a focus on both the amount of the actors in a hybrid and the relationship between these actors provides us a better understanding of hybrid forms of governance and their effects. The discussion is organized as follows. First, I discuss the theoretical underpinnings of hybrid forms of governance. I present existing frameworks of hybrids; and, based on literature on the ecology of organizations and ecosystems, provide an enhanced framework that distinguishes between different types of hybrids and the relationship between public and private sector service providers within these. In order to show the value of including this relationship to our research, I present an illustrative case study in which I look on one type of hybrid and two relationships within that hybrid type. The hybrid is public service delivery in Australian and Canadian construction policy, with a competitive relationship in Australia and a complementary relationship in Canada. Based on the illustrative case study I draw conclusions about the role of relationships between public and private sector service providers for our understanding of hybrids. It should be noted that the case study presented has an explorative character and is introduced for illustrative purposes only.

\section{Hybrid forms of governance}

Over the years we have witnessed a range of studies on the strengths and weaknesses of public service delivery by public sector agencies and by private sector agencies. It is not my aim here to provide a extensive discussion, as the topic has been discussed in great depth elsewhere (e.g. Hodge, 2000; Osborne \& Gaebler, 1992). I restrict myself to providing a brief overview in the form of a table summing up some of the main findings (see Table 1 ).

***Table 1 about here***

If anything becomes clear from these studies, it is that both public and private sector service providers have strengths and weaknesses. Depending on what choice is made, tradeoffs will occur between various competing democratic values. As such we seem to have remained where James Q. Wilson left us about 20 years ago when he touched upon the debate: "over whether government services are better supplied by private sector organizations than by public agencies" (Wilson, 1989, 347). Now, many will say this critical remark is not entirely true. Over the years the debate has moved beyond the opposite categories of pure public and pure private organization of service delivery - if there has ever been such things as "pure" public or "pure" 
private (cf. Rothstein, 1998, chapter 8). Current forms of public service delivery are often characterized by a certain mix of both public and private sector agencies, often referred to as hybrid forms of governance (Brandsen, van der Donk, \& Putters, 2005; Elsner, 2004; Evers, 2005; Lang, 2001; Lehmkuhl, 2008; Noorderhaven, 1995). This section first introduces existing models for analyzing such hybrids. These models are characterized by a focus on the agencies involved. The section continues by introducing a more enhanced model to analyze hybrids by including the relationship between these agencies.

\section{Existing typologies}

Following contemporary forms of governance, regulatory scholars have introduced a wide range of "grand ideas" to describe and analyze hybrids such as quasi-market arrangements (LeGrand \& Bartlett, 1993), public-private-partnerships (Hodge \& Greve, 2007), incorporation and concerted action (Huyse \& Parmentier, 1990), covenants and contracting (van den Heuvel, 1994), and a range of self-regulatory initiatives, such as co-regulation (Gunningham \& Grabosky, 1998), enforced self-regulation (Ayres \& Braithwaite, 1992), sanctioned self-regulation and coerced selfregulation (Price \& Verhulst, 2005), or mandated self-regulation and mandatory partial selfregulation (Rees, 1988). Although these scholars might be said to play a "language game" (Hodge \& Greve, 2007, 547-8), a close analysis of their work learns that they refer to truly different hybrids, which are typified by the "amount" of public and private sector involvement in a hybrid (cf. Van der Heijden \& De J ong, 2009). This is the first, and most analyzed, key dimension of hybrids.

Another close analysis of hybrids learns that they can roughly be split into three types:

1. hybrids in which every task comes to either a public or private sector agency referred to as solitaries throughout the article;

2. hybrids in which some or all tasks are taken up by a joint organization of public and private sector agencies - referred to as affiliations throughout the article; and

3. hybrids in which some or all tasks can come to both public and private sector agencies -referred to as optionals throughout the article.

Some examples might illustrate this point.

A classic example from the first type is the contracting out of services; for instance, waste collection. Under such a contracting regime rules and regulations for waste collection will be set by a public authority. Waste collection itself is carried out by one or more private sector agencies. Any oversights on this service delivery are taken up by a public agency, as is the dealing with complaints from service receivers - the general public. Here a number of public and 
private sector agencies work together within a hybrid waste collection regime. Yet, they all have clearly defined and non-overlapping tasks (example from: McDavid, 1985).

A classic example from the second type is public-private partnerships; for instance, the development and operation of highways. Under such a partnership rules and regulations for highways are set by a public authority. The development of plans for the highway will be jointly taken up by public and private sector agencies, as will the investment. The building of the highway will be taken up by a private sector agency, as will the operation of the highway. The income of this operation will either be split amongst the public and private sector agencies, or the private sector agency is allowed to only operate the highway for a certain period of time. Here a number of public and private sector agencies work together within a hybrid highway development and operation regime. In some levels of the regime they all have their own clearly defined and non-overlapping tasks; in other levels they jointly take up a single task. The public and private sectors merge into a single organization (example from: Vining, Boardman, \& Poschmann, 2005).

Finally the third type, a classic example of which is freedom of choice; for instance, primary schools. Under such a choice regime a public authority sets rules and regulation for primary schools. The operation of primary schools is taken up by public and private sector agencies. Contrary to the previous hybrid type, the public and private sector agencies do not work jointly, but operate their own schools as individual service providers. As such choice between public and private schools exist for service receivers (yet, critics to choice regimes state that choice often does not exist, or is limited by certain factors - a good overview of these factors is provided by Fotaki et al., 2008). In practice, the public and private sectors have to compete for clientele. Here a number of public and private agencies work together within a hybrid primary school regime. In some levels of the regime they all have their own clearly defined and nonoverlapping tasks; in other levels they individually take up a similar task (example from: Rothstein, 1998).

The separation of tasks within a hybrid shows us a second, but under-researched key dimension: the relationship between public and private sector agencies within a hybrid. We have at least seen 'merging' in the second example and 'competition' in the final example. Allow me to make an excursion into literature on the ecology of organizations and ecosystems, to gain insight into what types of relationships might exist between public and private sector agencies within a hybrid. $^{1}$

\section{Enhanced typology}

The presence of both public and private sector agencies within a hybrid reminds us of ecosystems. J ust as two or more species might share a single biotope, so do public and private 
sector agencies, in the above examples, share the task environment of a single hybrid. Furthermore, just as species that share a single biotope stand in a certain relationship, so do different agencies within their hybrid. In ecosystems literature this is referred to as symbioses.

Ecosystems literature initially defined symbioses in a narrow sense as a situation in which two or more dissimilar entities live in or on one another in an intimate relationship (Roossinck, $2008,157)$. In a broader sense, symbiosis is referred to as a situation in which two or more dissimilar entities share a single environment (Stachowicz, 2001). What is essential about symbiosis is that these dissimilar entities stand in a certain relationship and have to survive on limited resources. Ecologists distinguish three basic types: mutualism, commensalism and antagonism (Roossinck, 2008; Stachowicz, 2001). Mutualism is a situation in which both entities benefit from the relationship - this might also be a neutral or passive relationship. Commensalism is a situation in which one entity benefits from the relationship, whilst the other neither benefits nor is disadvantaged by the relationship. Antagonism is a situation in which one entity benefits from the relationship, whilst the other is disadvantaged - in extreme situations even both entities are disadvantaged by the relationship. Here we see a parallel with "variable-sum games": when one entity gains, the other does not have to lose per se (Schelling, 1980 [1960], 5).

In a hybrid similar effects might occur as a result of relationships between different agencies. This assumption is backed up by literature on organizational ecology. Scholars such as Barnard (1938, 101-3) and Jordan, Wurzel, and Zto $(2005,481)$ distinguish a number of possible relationships. Organizations can cooperate and complement one and other without merging into a new organization - this might be both an active and a passive relationship. Organizations can complement one and others by merging into a new organization - as such the relationship disappears. Organizations can compete for clientele without aiming at taking each other's place. Furthermore, organizations can compete for clientele aiming at taking each other's place - in which the relationship might disappear once one organization takes over the place of the other. These relationships shall be addressed as five types: cooperation, complementary, merging, competitive, and rivalry. All things being considered, these are relationships of a different nature. The nature of the relationship is considered from underlying mechanisms - cooperation, complementary and competitive; or from its intended outcome - merging and rivalry.

Cooperation, complementary and merging can be considered as mutualism or commensalism: either public sector agencies or private sector agencies, or both benefit from the relationship. Competitive and rivalry can be considered as antagonism: one sector's agencies benefit from the relationship, whilst the others are disadvantaged - in extreme situations even both sectors' agencies are disadvantaged by the relationship. Note that merging and rivalry are non-durable relationships: the goal of the relationship is to end the relationship. Note 
furthermore that some find that if the service provider suffers, its clients -receivers of public services - may also suffer from the relationship (cf. Hodge, 2000, chapter 2).

Then, if a relationship within a hybrid is durable the public and private sector agencies mutually have to survive on limited resources in their task environment. Again ecosystems literature provides inspiration: the aggressive or friendly invasion of a new species in a biotope. Besides the relationship that will develop between the native species and the invasive, the survival of the species will depend on their ability to adapt to the new situation. The new specie might suffer from native species as the latter consumes the limited resources present and might have an omnipotent presence; it might gain from specialization on unused resources, or develop the ability to outcompete the native species (cf. Schwarz, Matta, Shakir-Botteri, \& McPheron, 2005). Native species might suffer from the invading specie when resources have to be shared; it might have an advantage over the invading specie given its presence in and knowledge of its territory (cf. Walters \& Mackay, 2005).

Similar processes have been discussed in organization and implementation literature. A classic author from the field, Chester Barnard, noted in 1938 that organizations have to adapt and specialize in order to survive (Barnard, 1938, 91-92, chapter 10). Specialization can be achieved through technical expertise by minimizing efforts to gain resources (cf. Leibenstein, 1966), or by finding and exploiting a relevant niche (cf. Freeman \& Hannan, 1983). In public service delivery the resources in the task environment that have to be shared are service receivers - and, of course, their funds.

J ust like invasive species in a biotope might suffer from already present species, or have an advantage over it, so do agencies in a hybrid. For example, existing public agencies might suffer from a classic prejudice of being cumbersome, non-client friendly, and gridlocked (Eggers, 2005), or might gain from a good reputation built up in the past (Fombrun, 1995). Already present agencies in a task environment can, relatively easily, undertake protectionist measures since they are familiar with the field and its players (MacManus, 1992). At the same time new agencies might gain from knowledge of the situation, for instance by specializing on those aspects that fell short in the pre-hybrid situation (Wilson, 1989, 188-182) or cream off the profitable jobs (Van Slyke, 2003). Or, the newcomers might be very motivated to make the hybrid work, which might make them willing to work harder for less revenue than existing agencies (Sanderson, 2002).

Bringing all this together, and rounding up our excursion into literature on the ecology of organizations and ecosystems, it logically follows that certain relationship types come to certain hybrid types. First, in hybrid type 1, solitaries, there is no relationship of the kind described in this section between public and private sector agencies. If there is a relationship, it will be a principal-agent relationship, as is for example the case in contracting out. Note however that 
some of the relationships described in this section might exist amongst private sector agencies that aim to become service providers. Second, in hybrid type 2, affiliations, characterized by joint organization of public and private sector agencies, durable relationships might be merging or long term cooperative. A non-durable relationship may be temporarily cooperative, or "merging for the time being" (cf. Hill, Hitt, \& Hoskinsson, 1992). Here the analytical difficulty will be to distinguish amongst what counts as "long term" and what counts as "temporary". Finally, in hybrid type 3, optionals, the durable relationships between public and private sector agencies might be complementary or competitive. A non-durable relationship may be rivalry.

Table 2 provides an enhanced framework for studying hybrids. It presents a typology of hybrids, their arrangement of tasks, and the possible relationship(s) between public and private sector agencies that might exist in each type.

***Table 2 about here***

In the remainder of this article I use an illustrative case study to demonstrate how the enhanced framework may help us to gain a better understanding of hybrid forms of governance than by looking at the amount of public and private sector involvement only. I focus on one hybrid-type, hybrid type 3, and two relationships within that hybrid type, a competitive and complementary relationship between agencies. The study provides a better understanding of why the outcomes of two apparently comparable hybrids, when looking at the amount of public and private sector involvement only, differ as a result of different relationships within the two hybrids.

\section{I I Ilustrative case study: rationale, cases, and methodology}

This section introduces the reader into the background of the study. It begins with the theoretical rationale and continues with a brief introduction of the cases studied, and the methodology used for data collection and analysis.

\section{A. Rationale for the case study: comparing the impact of competitive and complementary relationships}

Competition has long been regarded as the incentive to improve effectiveness and efficiency of service delivery (Becker $\&$ Stigler, 1974; Landes \& Posner, 1975). Following these early advocates of competitive private sector involvement in public service delivery, Osborne and Gaebler in their highly influential work Reinventing Government (1992, p. 309) have advocated "market-oriented government" that should do "more steering and less rowing" (ibid, p. 103). These authors strongly advocated competition as relationship, because competition is expected to reward 
innovation - improving quality, keeping down costs - and would thus become an incentive to do so (ibid. 88-92, also Williamson, 1996, 119). Yet, over the years it has become clear that competition in public service delivery also has negative side effects. The accountability of competitive private sector senvice providers is frequently questioned (cf. May, 2007; Power, 1999). Further, as a result from a creaming attitude some find that not all service receivers are treated likewise when service providers have to compete for clientele, which may result in issues related to equity (Amirkhanyan, 2008; Morgan \& England, 1988).

A complementary relationship between public and private sector service providers has had less attention in governance studies. However, we are familiar with complementary relationships. Especially in self-regulation and voluntary programs literature we see that private sector organizations often introduce their own regulatory regimes in addition to public regulatory regimes. This is done for various reasons - for example to prevent the implementation of strict regulation by a public regulator, or to distinguish a group of organizations from other market players (e.g. Baldwin \& Cave, 1999; Potoski \& Prakash, 2009; Young, 2000). Such initiatives complement public regulatory regimes; and, following the terminology of this paper, hybridize such regimes.

As with competition different outcomes are reported on hybrids in which public and private sector service providers face a complementary relationship. Private sector actors may take up issues that would otherwise remain unresolved. A regime might therefore become more effective (cf. Potoski \& Prakash, 2009). Furthermore private sector actors are expected to be better able to address issues within their own sector, as they are more familiar with this environment than public sectors agencies are. A regime might therefore become more efficient (cf. Baldwin \& Cave, 1999, chapter 4). Also in these regimes accountability is considered an issue. Accountability strongly depends on the strength and enforcement of a voluntary or selfregulatory regime's rule system (cf. Potoski \& Prakash, 2009, chapter 2). This may result in comparable accountability issues as discussed under the competitive relationship. Equity, finally, may be a lesser issue under a complementary relationship. After all, a general level of regulation or service is provided by the public sector, and those wishing to set or receive a higher level may do so in the private sector (cf. Rothstein, 1998, chapter 8).

These studies however do keep a strong focus on the impact of private sector service providers as opposed to public sector service delivery - in the competitive relationship literature; or on the impact of a hybrid regime as opposed to a pure public regime - in the complementary relationship literature. The relationship between service providers appears more taken as a given than as a, or the, topic of inquiry in these studies. Thus, it is not surprising that in both strands of literature comparable findings are reported as they in practice only focus on the introduction of 
private sector service delivery in a former pure public regime. They learn us little about the impact of the relationship between public and private sector service providers in hybrids.

\section{B. Cases}

The context of the research is service delivery in Australian and Canadian construction policy. ${ }^{2}$ This context was chosen as in Australia and Canada certain construction policy related public services can be taken up by public and private sector agencies - they fit hybrid type 3 . The countries and the particular sector were chosen for their high comparability in hybrid environment and structure: the countries have a comparable government and judicial system (Dickerson \& Flanagan, 1998; Jackson \& Jackson, 2003); construction is regulated by comparable building codes (ABCB, 2004; NRCC, 2005); the countries have similarly divided tasks and responsibilities with regard to construction policy amongst national, regional and local governments (Hansen, 1985; Lovegrove, 1991) and private sector agencies (Van der Heijden, 2010a, 2010b); and finally, have an analogous approach towards the privatization of public services (Özkaya \& Askari, 1999).

There is, however, one major difference between the countries: in Australia a competitive relationship exists between the public and private sector service providers, providing clients - service receivers - a choice over who to involve in their construction work (PC, 2004). In Canada a complementary relationship exists between the public and private sector service providers. Public sector agencies may choose which services to deliver. Private sector agencies are allowed to take up those tasks which are not taken up by public sector agencies (Van der Heijden, 2010b).

The services delivered are the assessment of building plans against the building codes; the issuance of building permits when plan-assessment makes a reasonable case for compliance; the assessment of work under construction; and, the issuance of occupancy permits when construction work assessment makes a reasonable case for compliance. Note that building code assessment is typically a preventive strategy. As a result there is often no proof of full compliance; at best an acceptable level of certainty can be reached (cf. Sparrow, 2008).

A final reason to choose Australia and Canada as case studies is that in both countries private sector agencies have been introduced early on in the privatization movement - the 1980s in Canada, the 1990s in Australia. In both countries private agencies were introduced as an addition to a former "pure" public organization of service delivery. It may be expected that the growing pains of the implementation have been overcome, whilst at the same time many of those involved in the hybrids have experience with both the old "pure" public organization as with the "new" hybrids. This provides a unique chance to analyze how different dynamics for the 
hybrids, a competitive playing field in Australia and a more coordinated playing field in Canada, works out in practice.

\section{Data collection and analysis}

The question driving this research is how does a complementary or competitive relationship between public and private service providers affect service delivery? I approached this question using a qualitative research approach, as the strength of such an approach is exactly to explore "how" questions (see a variety of discussions in Brady and Collier 2004).

Both Australian and Canadian data are based on a series of semi-structured in-depth elite interviews (McCracken, 1988; Richards, 1996) to gain an understanding of why the new hybrid situation was implemented and how the new situation is experienced by different sets of actors. I interviewed policymakers who are responsible for introducing and overseeing hybrids to gain insight into issues relating to the accountability of those delivering services. I interviewed service providers, both public and private, to gain insight into how the delivery of services is experienced from a supply point of view. I interviewed service receivers - architects, engineers, contractors, representative bodies of the general public - to gain insight into how the delivery of services is experienced from a demand point of view. I selected interviewees using snowball sampling (Longhurst, 2003). This sampling resulted in a pool of potential interviewees from various backgrounds. Most (>90\%) having experience with the former "pure" public organization of service delivery and the "new" hybrid. Based on their availability and my presence in the countries I could interview 56 persons in Australia and 47 in Canada. Table 3 provides an overview of the interviewees' background and their role in the hybrid.

***Table 3 about here***

Interviews were based on a series of open-ended questions constructed around the following four main themes: Why was the hybrid introduced?; How does the hybrid operate in daily practice?; How is the hybrid evaluated?; Why are the goals that underpin the hybrid (not) achieved? Appendix A provides an overview of all interview questions. By continuously moving between these four main questions I aimed to cross-check validity between interviewees' answers during the interview - for instance it proved me with a structure to build in checks and balances within the in-depth interviews (cf. Silverman, 2001). On average interviews took 90 minutes. Interviews were recorded and transcribed into a report that I sent back to interviewees for validation (Fielding \& Fielding, 1986). Roughly three months after the interview, I sent a follow-up questionnaire stating 20 of the most frequently stated topics. For instance: "[private sector service delivery] and conflicts of interest go hand in hand due to commercial pressure". 
Interviewees were requested to react to these statements based on a four point forced Likertscale. As such I introduced the possibility to interviewees to react, to a certain extent, to each other's statements; and at the same time created the possibility to check the consistency between their interview statements and their agreement or disagreement with the questionnaire statements. Overall, these were consistent. Note that this statement questionnaire was returned by 27 (48\%) of Australian interviewees and 16 (35\%) of Canadian interviewees.

The final instrument for gathering data was the collection and analysis of existing research reports, government documentation, and inquiries on the topic. Contrary to my expectations I could not obtain extensive direct data that would strengthen the experiences as shared by the interviewees. Little to no records are kept on, for instance, building permits issued by public and private sector agencies; processing times; or, traced breaches with regulations.

In order to analyze the obtained data from the interviews, I coded these from rough to fine by means of a systematic three step coding scheme (cf. Seale \& Silverman, 1997; Silverman, 2001): I first coded interview data based on characteristics of the hybrid - for example competitive or complementary relationship - and the interviewee; second, I coded data based on the focus of the research questions - for example experienced changes in effectiveness, efficiency, equity or accountability compared to the prior situation; third, I coded data based on issues discussed - for example conflicts of interest, or commercial pressure. I used computer aided software, the program Atlas.ti, to run queries. By using this method I was able to treat pieces of information in a comparable and systemized manner, thus gaining insight into "repetitive" and "deviant" experiences. I used the data from the statement questionnaire to check the consistency of repetition of experiences. Overall, these were consistent. As I consider data from the statement questionnaire, compared to the interview data, to be provoked I have treated it for checking interview data validity only. In itself the statement questionnaire data does not add new information; it merely provides a quantification of interview data. Finally, QCA (qualitative comparative analysis, see Ragin, 2000; Ragin \& Strand, 2008) logic and tools were applied to trace patterns in the data.

To sum up, I interviewed a range of actors involved in the new hybrids. I posed a series of questions to gain insight into experienced changes of the new hybrid situation compared to the former pre-hybrid situation in the cases analyzed - this pre-hybrid situation was pure public service delivery in all cases. The findings presented in the following section should therefore be understood as elite experiences (cf. Lee \& Whitford, 2009).

\section{I llustrative case study: findings}

In order to show the relevance of the inclusion of the relationship between public and private sector service providers in the studies of hybrid forms of governance, this section presents three 
illustrative findings from the case study. More general findings on the strengths and weaknesses of privatizing service provision in construction policy in Australia and Canada are reported elsewhere (Van der Heijden, 2010a, 2010b).

In this section I will, to clearly distinguish between public and private sector service providers in the hybrids studied, use two abbreviations. MBCD refers to municipal building control departments, which are the public sector service providers in the hybrids analyzed. PSIA refers to private sector inspection agencies, the private sector service providers in the hybrids analyzed.

\section{A. Animosity versus cooperation}

Competition may be regarded both an instrument and a value. In the Australian cases competition appears introduced as a value, more than as an instrument (PC, 2004). Yet, this competition is taken very literally by those working in the new hybrids. Interviewees from all groups targeted referred to animosity between the two sectors' workers. An Australian public sector representative expressed this as: "The biggest pitfall in the system is the non-acceptance of private and council building surveyors of each other's work". Under the current Australian regimes it appears the competitive relationship has related in two fully separated groups of service deliverers, yet aiming at comparable goals: a safe, healthy and durable built environment. The groups have become strangers as an Australian private sector representative illustrates: "When we all worked-on under local government (...) there was a lot more sharing of knowledge and skills and it worked a lot better. Now there seem to be these two groups (...) and there's definitely a split between the two groups".

The Canadian narrative was different. The complementary relationship was experienced to result in cooperation between the groups. A Canadian public sector service provider sketched the scene as: "It's not competition; it's working side by side". Even more, Vancouver based PSIAs explained they involve MBCD staff when they are faced with non-compliance issues they cannot solve themselves; whereas the Vancouver MBCD fully relies on PSIAs to assess complex construction work. Canadian interviewees from both the public and private sectors stressed the importance of such cooperation as it made them aware of each other's strengths and knowledge.

Framing the relationship "aggressively" as competition, as done in Australia, clearly has a different impact than framing the relationship more friendly as complementary, as done in Canada. On a day-to-day basis it hampers interaction and learning between the groups through the sharing of the actual service providers' tacit knowledge (cf. de Bruijn, 2007). On the long run, as an Australian architect indicated, it may even have an impact on policy making: "Local government used to have a large role in the input of regulations. This was based on experiences in the field. Now the loopback from Council to State or Federal government has been lost." And, so she explained, PSIAs do not report issues they encounter in the field back to the Council, 
State or Federal government. Both on a day to day basis as on the long run this may negatively impact on the hybrids effectiveness.

\section{B. Overweight government versus lean government}

In both Australia and Canada PSIAs are capable of specializing in certain niche markets and therefore are able to provide specialist service - whereas MBCDs face difficulty in specializing since they have to deal with all work offered. An Australian service receiver explained: "If someone wants to build, say, a car-station or a major facility then [MBCDs] don't know how to deal with that. So you can bring in a specialist [PSIA]". Furthermore, PSI As often face less layers of administration than MBCDs do and can pay their staff to work extra hours - which often is impossible for MBCDs. As such PSIAs are generally able to provide a more specialized and speedy assessment process than MBCDs can.

As a result, in Australia clients involved in specialist or major works prefer PSIA involvement over MBCD involvement in their construction works. Yet, this resulted in a situation of MBCDs losing large amounts of revenue - fees for assessment and permit issuance are a percentage of the total building costs. In order to overcome this loss of revenue and win back the profitable jobs, MBCDs hire specialists alongside their generalist staff. MBCD staff is however location bound - they can only work within the MBCD's jurisdiction - whereas the specialists of PSIAs can work, like their clients with whom they often build a long term working-relationship, all over Australia. Clients involved in major construction work do therefore not appear to move back to MBCD involvement. In short, mismatches were reported between MBCDs capacity to provide service and services required.

In Canada, MBCDs have a choice as to what level of services to provide. In the case of the Greater Vancouver Regional District (population over two million), MBCDs only provide a general level of services, suitable to most clients involved in non specific, non complex works. Clients involved in specialists or major construction works are advised to have their work assessed by PSIAs. This has resulted in a situation in which MBCDs hold a specific kind of staff: generalists. As in Australia, clients involved in specialist or major construction works find their way to PSIAs. Compared to their Australian counterparts these Canadian MBCDs holds staff that is tailored to the level of service they provide and the specific group of clients they serve. A former chief of the Vancouver MBCD, a public sector service deliver, explained the advantaged of such tailoring: "If it wasn't for the [PSIAs] City Hall would have had to double staff now, and lay them off during slower times". The problem, so he continued, is that is difficult to lay off public staff.

The City of Vancouver's MBCDs can thus be regarded as fitting a trend of "lean government" (Haschold \& Von Otter, 1996). A relatively small and non-specialist staff is less 
expensive to maintain, than a somewhat too large and somewhat too specialist staff. The latter is the case at many Australian MBCDs. Here it can be argued that the competitive relationship in Australia results in an inefficient hybrid: unique means are not used for unique goals (Leibenstein, 1966).

\section{Activism versus passivism}

Hiring specialists is however not the only attempt of Australian MBCDs to win back their turf. Interviewees reported a trend of MBCDs taking over the characteristics of PSI As: providing more streamlined, more client friendly, and more knowledgeable services (cf. PC, 2004, 221; VCEC, 2005, 82). This confirms findings by Price (2007, 1149-1150) who reports likewise up skilling of public agencies in response of facing competitive private sector counterparts.

The Canadian narrative was, again, different. Instead of aiming to skill their services up to the level of PSIAs, the complementary relationship provided the Canadian MBCDs the possibility to take a different path. Two examples are illustrative. In the Greater Region of Vancouver MBCDs have specialized in minor and more general building works - often referred to as 'the moms and pops jobs', such as house alterations, carports and fences. This "specialization" may however be termed 'down skilling' since the MBCSs are unable to assess the more complex and major work, which they leave to PSIAs. As we have seen, this is considered a fruitful cooperation since the now lean MBCDs do not have to hold specialized, and thus, expensive staff. The example of the Province of Alberta provides some insight in what might happen if the MBCDs lose too much expertise and involvement.

In Alberta PSIAs were introduced expecting that a large number of small PSIAs would be scattered over the province. Over time, however, the larger PSI As started to buy out the smaller ones, resulting in a situation in which currently five PSI As hold the majority of the market. In parallel to this development, Albertan MBCDs left more and more work to PSIAs, with some MBCDs even fully stepping back from delivering construction policy related services. Yet, so explained a provincial official, the province has become too dependent on the PSIAs. With only a small number PSIAs in the field, the provincial government faces difficulties in "steering" their behavior when, for example, it is found their work does not meet legal standards. The strongest measure the provincial government can take is to withdraw a PSIA's license, which in practice means that it has to cease operations. However, taking an PSIA out would imply that construction policy related services will no longer be carried out in parts of the province. This provincial official therefore wondered, "What would we do if [PSIAs] close their doors?"

Although complaining that the requirements from the pre-hybrid situation - regulated fees, regulated wages, requirement to deal with all work provided - prevents them from fully competing with the PSIAs (NSW Parliament, 2002: 112-113), addressing competition as a value 
appears to have risen activism at the Australian MBCD level. Instead of down skilling and losing expertise, as their Canadian counterparts have, they still are a match to the PSIAs, providing the State and Federal governments some independency from the PSIAs. This might positively impact on the legitimacy and accountability of the hybrid as a whole: the MBCDs provide a necessary balance to PSI A involvement.

\section{Discussion and conclusions}

A current and much studied trend in public service delivery is hybridization. In a hybrid both public and private sector organizations are involved in service delivery. This paper discussed two key dimensions of hybrids: the proportion of public and private sector involvement, and the relationship between public and private sector organizations within a hybrid. As discussed, the former dimension has gained increasing attention in scholarship, both theoretically and empirically. The latter dimension has received little theoretical and even less empirical attention.

This paper adds to our understanding as it provided an enhanced framework for analyzing hybrid forms of governance and illustrated this with a comparative case study of a single hybrid type, but with two different relationships between the public and private sector service providers. The case study demonstrates that different relationships between public and private sector service providers may have a different impact on service delivery. This has relevance for both the theory and analysis of hybrids, and for policy making.

The case study shows that the relationship between public and private sector service providers may, for example, affect a hybrid's effectiveness or efficiency in reaching its underlying goals, or its legitimacy and accountability. For scholars researching hybrids this finding may not seem unique: comparable findings have been reported (see section 3). Yet, these findings are reported from research into the "amount" of public and private sector service delivery, not from specific research into the relationship between the sectors. Given that the relationship also affects senvice delivery, we may now question if previous literature does not draw too positive or too negative conclusions on the impact of the "amount" of public and sector involvement. After all, the impact the relationship has on the services delivered may strengthen or undo the impact the amount of public or private sector involvement has. Future research may be more aware of this understanding.

For policy making the paper implies that when considering to include private sector service delivers alongside public sector service delivers, not only choices should be made about what tasks these private sector agencies are allowed to take up; but also a choice needs to be made about the relationship between the public and the private sector. The case study presented here provided insight into some of the possible outcomes of different relationships in a single type of hybrid. More empirical research will be necessary to provide a more nuanced and more 
complete insight into how and how much different relationships affect service delivery. Only then an informed choice may be made on what solution to choose.

To conclude, in this paper I targeted a gap in our current knowledge on hybrid forms of governance. Many questions remain; some relevant are: to what extent, where and when is a certain relationship between public and private sector service providers preferable over the other? The answers to such questions are ultimately a matter for further empirical inquiry. Through this paper I only seek to put them on the research agenda.

J EROEN VAN DER HeIJ DEN is a Research Fellow at the Regulatory Institutions Network (RegNet); School of Regulation, Justice and Diplomacy; Australian National University; and an Assistant Professor at the Faculty of Technology, Policy and Management; Delft University of Technology. He holds a PhD in public policy; his research addresses regulatory policy.

\section{Footnotes}

1. One of the reviewers rightfully pointed out that the ecological school is but one in within organizational literature, more perspectives exist (for a good overview, see Pugh, 2007; Pugh \& Hickson, 2007).

2. Note that I have analyzed a selection of approaches to public and private sector service delivery in construction policy in Canadian and Australian jurisdictions - the units of analysis. In Australia these are South Australia, New South Wales, Victoria, the Australian Capital Territory and Queensland. In Canada these are Ontario, Alberta and the Greater Vancouver Regional District. When referring to Australia and Canada in the remainder of this paper, I refer to these cases only. 


\section{Tables}

Table 1 - Strengths and weaknesses of delivery of public services public and private sector agencies

Type of service delivery

Public sector

Private sector

\begin{tabular}{|c|c|c|}
\hline Strengths & $\begin{array}{l}\text { - Equity (Stone, 2002; Wilson, 1989) } \\
\text { - Force of law (Baldwin \& Cave, 1999; } \\
\text { Offe, 1984) } \\
\text { - Democracy (Bader \& Engelen, 2003; } \\
\text { Rothstein, 1998) }\end{array}$ & $\begin{array}{l}\text { - Efficiency (Osborne \& Gaebler, 1992; } \\
\text { Sparrow, 2000) } \\
\text { • Choice (Rothstein, 1998; Sen, 1988) } \\
\text { - Flexibility (Baldwin \& Cave, 1999; } \\
\text { Gunningham \& Grabosky, 1998) }\end{array}$ \\
\hline leaknesses & $\begin{array}{l}\text { - Inefficient (Bardach \& Kagan, 1982; } \\
\text { Sparrow, 2000) } \\
\text { • Inflexible (Baldwin \& Cave, 1999; } \\
\text { Bardach \& Kagan, 1982) } \\
\text { - Costly (Aalders \& Wilthagen, 1997; } \\
\text { Osborne \& Gaebler, 1992) }\end{array}$ & $\begin{array}{l}\text { - Conflicting interests (Gunningham \& } \\
\text { Grabosky, 1998; Hodge \& Coghill, 2007) } \\
\text { - Segregation (Morgan \& England, 1988; } \\
\text { Van Slyke, 2003) } \\
\text { - Accountability shortfalls (Adams \& Evans, } \\
\text { 2004; May, 2007) }\end{array}$ \\
\hline
\end{tabular}

Table 2 - Overview of hybrid types, arrangement of tasks and possible relationships between public and private sector agencies

\begin{tabular}{|l|l|l|l|}
\cline { 2 - 4 } \multicolumn{1}{c|}{} & \multicolumn{3}{c|}{ Hybrid type } \\
\cline { 2 - 5 } & Type 1: Solitaries & Type 2: Affiliations & Type 3: Optionals \\
\hline $\begin{array}{l}\text { Arrangement of } \\
\text { tasks }\end{array}$ & $\begin{array}{l}\text { Contracting out } \\
\text { (McDavid, 1985) }\end{array}$ & $\begin{array}{l}\text { Public-private- } \\
\text { partnership } \\
\text { (Vining et al., 2005) }\end{array}$ & $\begin{array}{l}\text { Freedom of choice } \\
\text { (Rothstein, 1998) }\end{array}$ \\
\hline $\begin{array}{l}\text { sector agencies all } \\
\text { have clearly defined } \\
\text { and non-overlapping } \\
\text { tasks }\end{array}$ & $\begin{array}{l}\text { In some levels of the } \\
\text { regime public and } \\
\text { private sector } \\
\text { agencies all have their } \\
\text { own clearly defined } \\
\text { and non-overlapping } \\
\text { tasks; in other levels }\end{array}$ & $\begin{array}{l}\text { In some levels of the } \\
\text { regime public and } \\
\text { private sector } \\
\text { ann clear defined and } \\
\text { own-overlapping tasks; } \\
\text { in other levels they }\end{array}$ \\
\hline
\end{tabular}




\begin{tabular}{|l|l|l|l|}
\hline & & $\begin{array}{l}\text { they jointly take up a } \\
\text { single task. }\end{array}$ & $\begin{array}{l}\text { individually take up } \\
\text { similar tasks }\end{array}$ \\
\hline Possible public- & None* & $\bullet$ Merging (durable or & $\bullet$ Cooperation \\
private sector & & non-durable) & $\bullet$ Complementing \\
relationship & & $\bullet$ Cooperation (long & $\bullet$ Competing \\
& & term and & $\bullet$ Rivaling \\
& & temporary) & \\
\hline
\end{tabular}

* Note: relationships might exist amongst private sector service providers within the hybrid. The focus of this paper is however on relationships between public and private sector service providers.

Table 3 - Overview of interviewees

\begin{tabular}{|l|l|l|c|c|}
\cline { 2 - 5 } \multicolumn{1}{l|}{ Interviewees' role in hybrid } \\
\hline I nterviewees' background & $\begin{array}{l}\text { Involved in } \\
\text { policymaking }\end{array}$ & $\begin{array}{l}\text { Delivering } \\
\text { services }\end{array}$ & $\begin{array}{l}\text { Receiving } \\
\text { services }\end{array}$ & Other \\
\hline Public official (including MBCD staff) & $27(14 / 13)$ & $21(10 / 11)$ & & \\
\hline Private sector representative & $5(2 / 3)$ & & $11(6 / 5)$ & \\
\hline PSIA staff & & $14(9 / 5)$ & $13(7 / 6)$ & \\
\hline Architect/engineer & & & $5(1 / 4)$ & \\
\hline Builder/contractor/developer & & & $29(14 / 15)$ & $7(7 / 0)$ \\
\hline Other professions & & $35(19 / 16)$ & & 7 \\
\hline Academic & & & & \\
\hline Total & $32(16 / 16)$ & & & \\
\hline Total number of interviewees: $103(56 / 47)$ & & & \\
\hline
\end{tabular}

Note: The numbers between brackets represent number of Australian/Canadian interviewees. 


\section{Appendix A - Ovenview of the main research questions (topic and question numbers)}

Introduction

la What do you think about the quality of the building industry in [jurisdiction]?

1b To what extent is a certain development perceivable in the building industry?

Why was the new regime introduced?

2. Preceding this interview I sent you a short overview, my perception, of the [old and new regime] in [jurisdiction]. To what extent is this an accurate description?

3a Why was the [new regime] introduced?

How does the regime operate in daily practice?

5a To what extent can [local government] interfere in the [private sector] assessment process?

$5 \mathrm{~b} \quad$ And to what extent does [local government]?

6 To what extent has compliance (with building regulations) changed after the introduction of [the new regime]?

7a To what extent can acceptable evidence be found of the achievement of regulatory objectives?

7b Could you state websites, research reports or articles that might be of help to my further research?

9a To what extent is building control performed equally amongst different groups?

9b To what extent is building control performed equitably by the different sectors (public and private sector enforcement actors)?

How is the regime evaluated?

3b Do applicants show a preference for either [public or private sector involvement]?

3c If so, why?

4a What are the criteria to be allowed to enforce building regulations (for both public and private sector actors)?

4b. Are these criteria realistic (qualitatively and quantitatively)?

10a What are the statutory responsibility and liability of different enforcement parties (public and private sector actors)?

$10 \mathrm{~b} \quad$ Are these realistic?

11a How are the different enforcement actors (public and private) overseen by [different levels of government]?

11b To what extent is this oversight realistic?

Why are goals that underpin the regime (not) achieved?

1c Why is building control needed in [jurisdiction]?

$8 \mathrm{a} \quad$ What is the most serious obstacle to achieving objectives of the building regulations?

Why?

$8 \mathrm{~b} \quad$ What is the second most serious obstacle to achieving objectives? Why?

8c [If the interviewee mentions more objectives, try to have these ordered.]

12 If you were allowed to change one thing in the new regime, what would it be? And why?

Final question

13 Is there anything you think I have missed in this interview, or is there anything you wish to add? 


\section{References}

Aalders, M., \& Wilthagen, T. (1997) "Moving Beyond Command and Control: Reflexivity in the Regulation of Occupational Safety and Health and the Environment," Law and Policy, 19: 415443.

ABCB. (2004) BCA 2004. Canberra: Australian Building Codes Board.

Adams, Carol A., \& Evans, Richard. (2004) "Accountability, Completeness, Credibility and the Audit Expectations Gap," The Journal of Corporate Citizenship, 14: 97-115.

Amirkhanyan, Anna. (2008) "Privatizing Public Nursing Homes: Examining the Effects on Quality and Access," Public Administration Review, 68: 665-680.

Ayres, Ian, \& Braithwaite, John. (1992) Responsive Regulation. Transcending the Deregulation Debate. New York: Oxford University Press.

Bader, Veit, \& Engelen, Edwald R. (2003) "Taking Legal Pluralism Seriously: Arguing for an Institutional Turn in Political Philosophy," Philosophy Social Criticism, 29: 375-406.

Baldwin, Robert, \& Cave, Martin. (1999) Understanding Regulation. Theory, Strategy and Practice. New York: Oxford University Press.

Bardach, Eugene, \& Kagan, Robert A. (1982) Going by the book: the problem of regulatory unreasonableness. Philadelphia: Temple University Press.

Barnard, Chester Irving. (1938) The functions of the executive 1968, 30th anniversary edition ed. Cambridge: Harvard University Press.

Becker, Garry S., \& Stigler, George J . (1974) "Law Enforcement, Malfeasance, and Compensation of Enforcers," Journal of Legal Studies, 3: 1-18.

Brandsen, Taco, van der Donk, Wim, \& Putters, Kim. (2005) "Griffins or Chameleons? Hybridity as a permanent and I nevitable Characteristics of the Third Sector," International Journal of Public Administration, 28: 749-765.

de Bruijn, Hans. (2007) Managing performance in the public sector. 2nd edition. New York: Routledge.

Dickerson, Mark O., \& Flanagan, Thomas. (1998) An Introduction to Government and Politics: $A$ Conceptual Approach. Scarborough: International Thomson Publishing.

Eggers, William D. (2005) Government 2.0 using technology to improve education, cut red tape, reduce gridlock, and enhance democracy. Lanham: Rowman \& Littlefield.

Elsner, Wolfram. (2004) "The new economy: complexity, coordination and a hybrid governance approach," International Journal of Social Economics, 31: 1029-1049.

Evers, Adalbert. (2005) "Mixed Welfare Systems and Hybrid Organizations: Changes in the Governance and Provision of Social Services," International Journal of Public Administration, 28: 737-748.

Fielding, N.G., \& Fielding, J.L. (1986) Linking Data. London: Sage. 
Fombrun, Charles J . (1995) Reputation. Realizing Value from the Corporate Image. Boston: Harvard Business School Press.

Fotaki, Marianna, Roland, Martin, Boyd, Alan, McDonald, Ruth, Scheaff, Rod, \& Smith, Liz. (2008) "What benefits will choice bring to patients? Literature review and assessment of implications," Journal of Health Services Research \& Policy, 13: 178-184.

Freeman, J ohn, \& Hannan, Michael T. (1983) "Niche Width and the Dynamics of Organizational Populations," The American Journal of Sociology, 88: 1116-1145.

Gunningham, Neil, \& Grabosky, Peter. (1998) Smart Regulation. Designing Environmental Policy. Oxford: Oxford University Press.

Hansen, A. T. (1985) The regulation of building construction. Ottawa: National Research Council Canada.

Haschold, Frieder, \& Von Otter, Casten. (1996) Public Sector Transformation: rethinking markets and hierarchies in government. Amsterdam: J ohn Benjamin Publishing.

Hill, Charles W.L., Hitt, Michael A., \& Hoskinsson, Robert E. (1992) "Cooperative versus Competitive Structures in Related and Unrelated Diversified Firms "Organization Science, 3: $501-522$.

Hodge, Graeme A. (2000) Privatization: An International Review of Performance. Boulder: Westview Press.

Hodge, Graeme A., \& Coghill, Ken. (2007) "Accountability in the Privatized State," Governance, 20: 675-702.

Hodge, Graeme A., \& Greve, Carsten. (2007) "Public-Private Partnerships: An international performance review," Public Administration Review, 67: 545-558.

Huyse, Luc, \& Parmentier, Stephan. (1990) "Decoding codes: The dialogue between consumers and suppliers through codes of conduct in the European Community," Journal of Consumer Policy, 13: 253-272.

J ackson, Robert J., \& J ackson, Doreen. (2003) An Introduction to Political Science: comparative and world politics. Toronto: Prentice Hall.

J ordan, Andrew, Wurzel, Rüdiger K. W., \& Zito, Anthony. (2005) "The Rise of New Policy Instruments in Comparative Perspective: Has Governance Eclipsed Government?," Political Studies, 53: 477-496.

Landes, William M., \& Posner, Richard A. (1975) "The Private Enforcement of Law," The Journal of Legal Studies, 4: 1-46.

Lang, J ochen. (2001) "Improving Structural Policy Under Conditions of Hybrid Governance," Evaluation, 7: 7-23.

Lee, Soo-Yong, \& Whitford, Andrew B. (2009) "Government Effectiveness in Comparative Perspective," Journal of Comparative Policy Analysis, 11: 249-281.

LeGrand, J ulian, \& Bartlett, Will. (1993) Quasi-Markets and Social Policy. Houndsmills: Macmillan. 
Lehmkuhl, Dirk. (2008) "Control Modes in the Age of Transnational Governance," Law \& Policy, 30: 336-363.

Leibenstein, Harvey. (1966) "Allocative Efficiency vs. X-efficiency," American Economic Review, 56: 392-415.

Longhurst, Robyn. (2003) "Semi-structured Interviews and Focus Groups," In Key methods in geography, edited by N. J. Clifford \& G. Valentine. London: Sage Publishers.

Lovegrove, Kim. (1991) The Primary Building Acts of Australia. A Comparative Study. Sydney: The Federation Press.

MacManus, Susan A. (1992) "Government contracting and procurement: a critical process for both the public and private sectors," International Journal of Public Administration, 15: 12131240 .

May, Peter J. (2007) "Regulatory regimes and accountability," Regulation \& Governance, 1: 8-26.

McCracken, Grant (1988) The long intenview Vol. 13. London: Sage.

McDavid, J ames C. (1985) "The Canadian Experience with Privatizing Residential Solid Waste Collection Services," Public Administration Review, 45: 602-608.

Morgan, David R., \& England, Robert E. (1988) "The Two Faces of Privatization," Public Administration Review, 48: 979-987.

Noorderhaven, Niels G. (1995) "Transaction, Interaction, Institutionalization: Toward a dynamic theory of hybrid governance," Scandinavian Journal of Management, 11: 43-55.

NRCC. (2005) National building code of Canada, 2005. Ottawa: National Research Council Canada.

NSW Parliament. (2002) Report upon the quality of buildings. Sydney: Parliament of NSW.

Offe, Claus. (1984) Contradictions of the Welfare State. London: Huntchinson \& Co.

Osborne, David, \& Gaebler, Ted. (1992) Reinventing government: how the entrepreneurial spirit is transforming the public sector. Reading: Addison-Wesley Publishers.

Özkaya, Mehmet, \& Askari, Hossein. (1999) "Management of Newly Privatized Companies: Its Importance and How Little We Know," World Development, 27: 1097-1114.

PC. (2004) Reform of building regulation. Melbourne: Productivity Commission, Commonwealth of Australia.

Potoski, Matthew, \& Prakash, Aseem. (2009) Voluntary Programs: a club theory perspective. Cambridge: MIT Press.

Power, Michael. (1999) The Audit Society: Rituals of Verification. Oxford: Oxford University Press.

Price, Byron E. (2007) "The Treat of Privatization: The Impetus Behind Government Performance," International Journal of Public Administration, 30: 1141-1155. 
Price, Monroe Edwin, \& Verhulst, Stefaan. (2005) Self-regulation and the Internet. The Hague: Kluwer Law International.

Pugh, Derek Salman. (2007) Organization theory selected classic readings. London: Penguin.

Pugh, Derek Salman, \& Hickson, David J . (2007) Writers on organizations. Sixt edition. London: Penguin Books.

Ragin, Charles C. (2000) Fuzzy-Set Social Science. Chicago: University of Chicago Press.

Ragin, Charles C., \& Strand, Sarah Ilene. (2008) "Using Qualitative Comparative Analysis to Study Causal Order: Comment on Caren and Panofsky (2005)," Sociological Methods and Research, 36: 431-441.

Rees, J oseph V. (1988) Reforming the workplace a study of self-regulation in occupational safety. Philadelphia: University of Pennsylvania Press.

Richards, D. (1996) "Elite Interviewing: Approaches and Pitfalls," Politics, 16: 199-204.

Roossinck, Marilyn J . (2008) "Symbiosis, Mutualism and Symbiogenesis," In Plant Virus Evolution, edited by M. J. Roossinck. Berlin: Springer.

Rothstein, Bo. (1998) Just Institutions Matter: The Moral and Political Logic of the Universal Welfare State. New York: Cambridge University Press.

Sanderson, Ian. (2002) "Evaluation, policy learning and evidence-based policy making," Public Administration, 80: 1-22.

Schelling, Thomas C. (1980 [1960]) The Strategy of Conflict. Cambridge: Harvard University Press.

Schwarz, Dietmar, Matta, Benjamin M., Shakir-Botteri, Nicole L., \& McPheron, Bruce A. (2005) "Host shift to an invasive plant triggers rapid animal hybrid speciation," Nature, 436: 546-549.

Seale, Clive, \& Silverman, David. (1997) "Ensuring rigour in qualitative research," European Journal of Public Health, 7: 379-384.

Sen, Amartya. (1988) "Freedom of Choice: Concept and Content," European Economic Reciew, 32: 269-294.

Silverman, David. (2001) Interpreting Qualitative Data. 2nd edition. London: Sage.

Sparrow, Malcolm K. (2000) The Regulatory Craft. Controlling Risks, Solving Problems, and Managing Compliance. Washington: Brookings Institution.

Sparrow, Malcolm K. (2008) The Character of Harms. Operational Challenges in Control. Cambridge; New York: Cambridge University Press.

Stachowicz, J ohn. J. (2001) "Mutualism, Facilitation, and the Structure of Ecological Communities," Bioscience, 51: 235-246.

Stone, Deborah A. (2002) Policy Paradox. The art of political decision making Revised Edition ed. New York: Norton. 
van den Heuvel, J. H. J. (1994) Overheid en beleid in Nederland feiten en inzichten vanuit de beleidswetenschap. Utrecht: Het Spectrum.

Van der Heijden, Jeroen. (2010a) "On Peanuts and Monkeys: Private Sector Involvement in Australian Building Control," Urban Policy and Research, 28: 195-2101.

Van der Heijden, Jeroen. (2010b) "One task, a few approaches, many impacts: private sector involvement in Canadian building control," Canadian Public Administration, 53: 351-374.

Van der Heijden, Jeroen, \& De J ong, Jitske. (2009) "Towards a better understanding of building regulation," Environment and planning B, Planning \& Design, 36: 1038-1052.

Van Slyke, David M. (2003) "The Mythology of Privatization in Contracting for Social Services," Public Administration Review, 63: 296-315.

VCEC. (2005) Housing Regulation in Victoria: Building Better Outcomes, Victorian Competition and Efficiency Commission, Final Report. Melbourne: Victorian Competition and Efficiency Commission.

Vining, Aidan, Boardman, Anthony, \& Poschmann, Finn. (2005) "Public-private partnerships in the US and Canada: "There are no free lunches"," Journal of Comparative Policy Analysis: Research and Practice, 7: 199-220.

Walters, A.C., \& Mackay, D.A. (2005) "Importance of large colony size for successful invasion by Argentine ants (Hymenoptera: Formicidae): Evidence for biotic resistance by native ants," Austral Ecology, 30: 395-346.

Williamson, Oliver E. (1996) The mechanisms of governance. New York: Oxford University Press.

Wilson, James Q. (1989) Bureaucracy. What Government Agencies Do and Why They Do It. New York: Basic Books.

Young, Dennis R. (2000) "Alternative Models of Government-Nonprofit Sector Relation:

Theoretical and International Perspectives," Nonprofit and Voluntary Sector Quarterly, 29: 149-

172. 